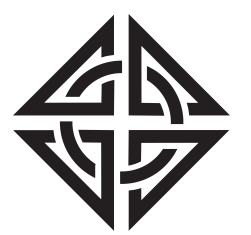

SCIENTIA

I RA N I C A

\section{Sharif University of Technology}

Scientia Iranica

Transactions D: Computer Science \&f Engineering and Electrical Engineering

http://scientiairanica.sharif.edu

\title{
Optimal electromagnetic-thermal design of a seven-phase induction motor for high-power speed-control applications
}

\author{
Z. Heidari ${ }^{\mathrm{a}}$, H. Gorginpour ${ }^{\mathrm{b}, *}$, and M. Shahparastic \\ a. Department of Electrical Engineering, Bushehr Branch, Islamic Azad University, Bushehr, Iran. \\ b. Department of Intelligent Systems Engineering and Data Science, Persian Gulf University, Bushehr, Iran. \\ c. Department of Engineering, East Tehran Branch, Islamic Azad University, Tehran, Iran.
}

Received 10 December 2019; received in revised form 26 October 2020; accepted 4 January 2021

KEYWORDS
7-phase induction
motor;
Optimization;
Coupled-circuit
model;
Lumped parameter
thermal model;
Finite-element
method;
Winding function.

\section{Introduction}

Multi-phase electric drives refer to electric machines having stator windings and more than three power

\footnotetext{
*. Corresponding author.

E-mail addresses: nariman_azma@yahoo.com (Z. Heidari);

h_gorgin@pgu.ac.ir (H. Gorginpour);

mshahparasti@yahoo.com (M. Shahparasti)
}

doi: $10.24200 /$ sci.2021.54766.4028

\begin{abstract}
Induction motors were traditionally used in industrial applications ranging from a fraction of horse-power up to several Megawatts due to their substantial benefits. Induction drives with more than three phases are superior to the 3-phase induction drives in terms of overall volume, torque fluctuations, current passing each stator-winding, ohmic loss, efficiency, and reliability in the case of stator-windings open-circuit fault. These benefits are particularly more attractive in variable speed drivers due to the reduced capacity of power-electronic switches. This paper aims to develop an optimal electromagnetic-thermal design procedure of a high-power seven-phase induction motor suitable for variable-speed applications. In this multi-objective design approach, the objective function is defined aiming to increase the efficiency, power-factor, power-toweight ratio, and starting-torque as well as reduce the starting-current. Furthermore, the electrical, mechanical, dimensional, magnetic, and thermal limitations are included in this optimization study in order to ensure practical realization of the designed machine. The coupled-circuit method is employed for nonlinear electromagnetic modeling, while the current displacement phenomenon is considered in calculations of rotor parameters. A lumped-parameter-thermal model is established for calculating heat rises of different parts at each iteration of optimization study. Finally, the performance characteristics of the optimally designed 1-MW 4-pole motor are verified based on 2D FE analyses.
\end{abstract}

(C) 2022 Sharif University of Technology. All rights reserved. 
Of note, the price of power-electronic drive is almost two times the price of electric motor and severely increases with increase in the rated voltage and power. Since the advent of multi-phase motors, extensive researches have been carried out on different issues associated with these machines. These researches are focused on areas including power-electronics supply, sensor-less controls, and other torque control methods. Hence, in recent years, multi-phase motors have made a significant progress in different areas including machine design and control.

The invention of multi-phase motors dates back to 1969 when a 5-phase inverter was employed to supply an induction motor drive [1]. The theory and experimental results of multi-phase motors are provided in $[2,3]$ in 1983. Next research was carried out in 1990 and two papers were published on operating characteristics of this type of motors [4,5]. Multi-phase motors have considerable advantages in comparison to 3 -phase motors, including high power-capacity, less torque fluctuations and consuming current magnitude of each phase for delivering a specified output mechanical power, less ohmic loss, higher efficiency and reliability, and better torque-per-ampere ratio. Another advantage of these motors is related to the power electronics inverter and its cost. Since the power is divided among more than three phases, less current flows through power electronics switches in variable-speed applications, leading to lower cost of the inverter [6-8]. Another important advantage of multi-phase motors is the possibility of injecting harmonics into the air gap flux density, which allows better torque control at different speeds than the 3-phase motors and results in smoother torque waveform with less ripple. Since it is applicable to create 3 th and 5 th harmonics into the magnetic field of the 7-phase motor, smoother torque and lower ripple in comparison to the 3-, 5-, and 6-phase motors can be reached and a better degree of freedom is introduced in terms of control [9]. Also, multi-phase motors exhibit better performance under fault conditions than conventional 3-phase motors. Given the several advantages and capabilities of multi-phase machines, particularly increased reliability, they are suitable drives to be employed in industrial plants such as oil and gas industries and nuclear power-plants and applications such as electric vehicles, electric trains, ship's engine, and submarine propulsion engine [8-10].

In [11], authors conducted an optimized design study for a 6-phase motor mounted on a compressor. This motor has a copper rotor winding and its optimum structure is obtained using a multi-objective optimization procedure. In this study, improvement of starting current, construction cost, and power factor are taken into account. A general model is proposed for a 5-phase motor in [12] considering air gap magnetic field harmonics. The presented model is a mathematical model in which time and spatial harmonics are taken into account. The model validity is investigated using finite element method and the results are verified through comparison with the experimental test results. In [13], the bifurcation analysis of a 5-phase inductionmotor drive was presented when the third harmonic was injected for torque-enhancement purposes. The main idea of the referenced study [13] is to establish a mathematic study of the nonlinear dynamics of the proposed drive with torque enhancement. The model is analyzed for both concentrated and distributed winding machines with harmonic injection, showing enhancement in operating quantities of multi-phase motors compared to the 3 -phase machine.

The design and control of a multi-phase induction machine were investigated in [14]. In this paper, a 6phase motor is designed and manufactured and several tests are performed. The $\mathrm{d}-\mathrm{q}$ model of the machine has also been obtained. The design performed in this study is a traditional design procedure. It should be noted that several population-based optimization algorithms, e.g., Particle Swarm Optimization (PSO), Genetic Algorithm (GA), Imperialist Competitive Algorithm (ICA), and several analytical models, have been used for design optimization of electric machines [15]. A review of recent advances in the control and design of multi-phase induction machines is the subject of [16] and [17]. In [16], the benefits and applications of multiphase machines were highlighted and it was mentioned that they made a remarkable and significant progress in recent years. Other topics discussed in these papers are the control system improvements and the field orientation control method [16,17].

Among multi-phase induction motors, the sevenphase motor is more desirable in terms of degree of freedom in control due to the possibility of injecting 3 th and 5th current harmonics in comparison with 3-, 5-, and 6-phase motors [17]. Furthermore, compared with motors carrying more than seven phases, the motor construction and winding operation as well as power supply arrangement are simpler and more practical. It should be noted that conventional multiphase machines are built in $5,6,7,9,11$, and 15 phases. As the phase number increases, the amount of motor winding amperage is reduced and the degree of freedom of control systems increases. In addition, the harmonic-order injected to air-gap can be increased to improve the field density waveform (Figure 1). In fact, an injected harmonic current with the same order as the order of spatial harmonic component of Winding Function (WF) creates a rotating magnetic field with synchronous speed equal to the synchronous speed of fundamental air-gap field. The relations between airgap flux density $\left(B_{m}\right)$ and yoke flux density $\left(B_{y}\right)$ with harmonic current injection are expressed as Eqs. (1) and (2), respectively [10]: 


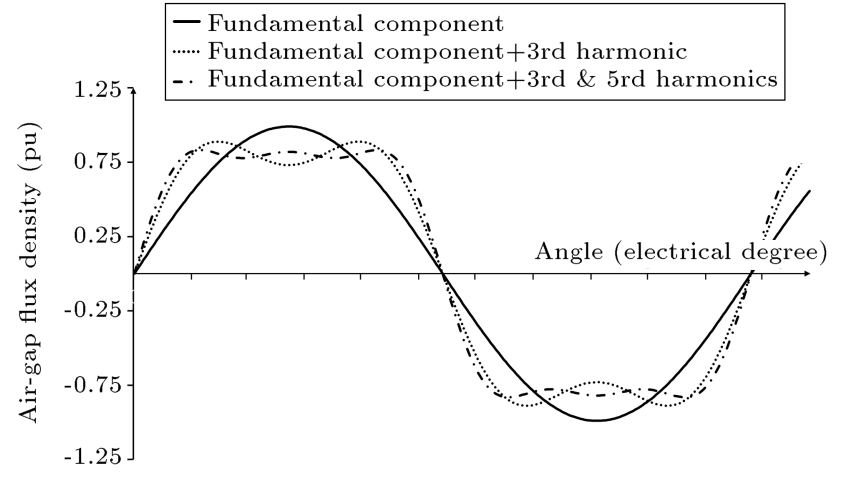

Figure 1. Effect of air-gap field harmonics created from stator current time-harmonics and winding-function spatial harmonics with the same orders in reduction of air-gap field magnitude [10].

$$
\begin{aligned}
B_{m}= & B_{m 1}\left(\sin \left(\varphi_{s}\right)+C_{3} \sin \left(3 \varphi_{s}\right)\right. \\
& \left.+\ldots+C_{k} \sin \left(k \varphi_{s}\right)\right) \\
B_{y}= & B_{y 1}\left(\cos \left(\varphi_{s}\right)+\frac{C_{3}}{3} \cos \left(3 \varphi_{s}\right)\right. \\
& \left.+\ldots+\frac{C_{k}}{k} \cos \left(k \varphi_{s}\right)\right)
\end{aligned}
$$

where $B_{m 1}$ is the fundamental component magnitude of air-gap flux density, $B_{y 1}$ fundamental component magnitude of yoke flux density, $C$ harmonic flux density coefficient, $k$ harmonic plane order, and $\varphi_{s}$ spatial electric angle. These coefficients can be optimally evaluated by using optimization method such as GA. There are two harmonic currents that can be utilized in 7phase induction motors, i.e., third and fifth harmonics. According to (Figure 1), the air-gap flux density has an improved waveform when third and fifth harmonics are injected. Obviously, peak value of $B_{m}$ is decreased by $5.54 \%$ and maximum value of $B_{y}$ is also reduced by $4.99 \%$, indicating that $B_{m 1}$ can be enlarged by $5.1 \%$ without iron saturation and it was revealed in [10] that the iron utilization and torque density were enhanced. On the other hand, the control system complexity grows as the number of phases increases. Therefore, considering the above-mentioned issues, the number of phase windings in this study is selected as 7 .

In this paper, electromagnetic-thermal design optimization of a 7-phase induction motor is presented and a comprehensive analysis is conducted. The stator winding of a 7-phase induction motor is fully designed; the turn function and WF of stator and rotor have been obtained and the coupled-circuit model is derived in order to analytically calculate the operating quantities considering the effect of current displacement phenomenon and core saturation construction.
Also, lumped parameter thermal model of the studied motor is established for calculating temperature rises in each design iteration. In the following, the objective function, optimization variables, and mechanical, electrical, dimensional, thermal, and magnetic limits are presented. The construction parameters of a 7 phase 1-MW motor have been optimally obtained using the proposed optimal design flowchart and its performance characteristics are verified using 2D timestepping finite element method.

The novelty and contribution of this paper is proposing an electromagnetic-thermal design optimization procedure for high-rated 7-phase induction motor considering practically appropriate magnetic, thermal, and construction constraints. For analytical calculation of machine performance and temperature rise, coupledcircuit model and lumped-parameter thermal model are established considering the special structure of large induction motors, axial and radial cooling ducts, stator winding and insulation requirements, and current displacement phenomenon in rotor bars.

\section{Motor design}

The optimal design procedure can be performed considering different objectives and constraints. The design stage is subject to limitations in technical and economic terms. Basically, the design procedure involves determination of geometries and dimensions of different parts, weight, material characteristics, output parameters, and operation characteristics under international standards. Important design parameters include high efficiency, low weight, low cost, desired power factor, and low temperature rise. The traditional design method can be effectively used at the initial design stage. The flowchart of the traditional design of induction motor is illustrated in Figure 2.

The machine dimensions are dependent on a number of items including torque in the specified speed, machine cooling method, machine startup/shutdown frequency, machine load operation cycle, magnetic and electric circuits, and the location where the machine is supposed to operate [18]. The machine overall dimensions, stator slot structure are, configuration of stator, and rotor slots are depicted in Figure 3. The meaning of each symbol in this figure is also described in Table 1.

The apparent power and air-gap flux density are obtained using Eqs. (3) and (4) [19]:

$$
\begin{aligned}
& S[V . A]=11 K_{w} B_{g} C L n D^{2}, \\
& B_{g}[T]=2 p \varphi_{m} / \pi D_{a g} l_{f e},
\end{aligned}
$$

where $K_{w}$ is winding factor, $B_{g}$ air-gap flux density, $C$ electromagnetic utilization, $n$ synchronous speed, 


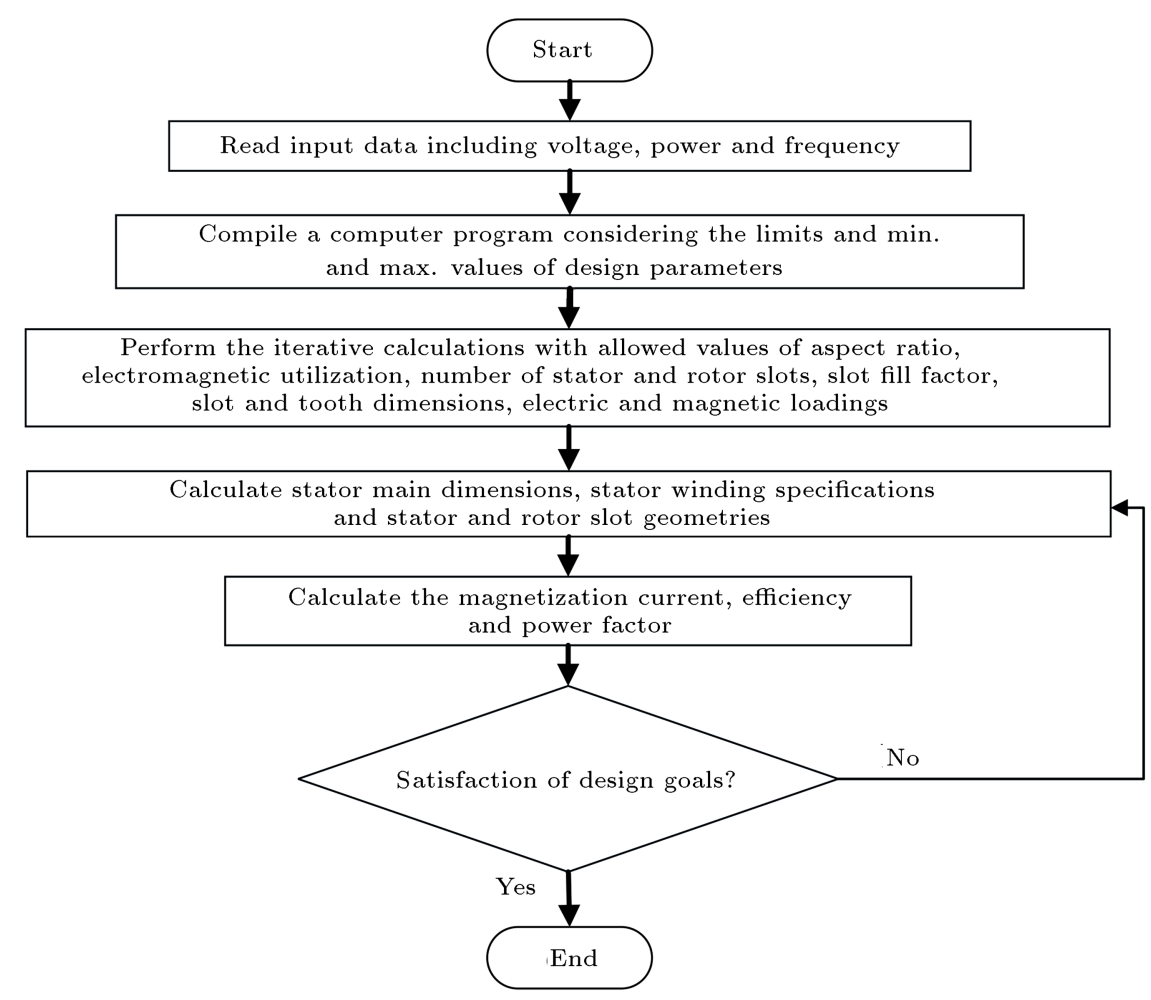

Figure 2. Flowchart of the induction motor traditional design.

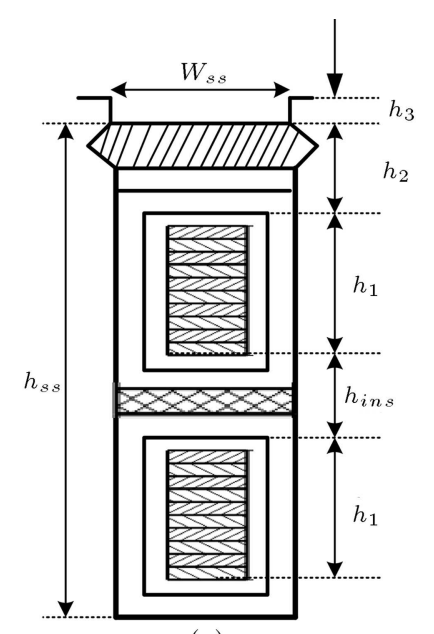

(a)

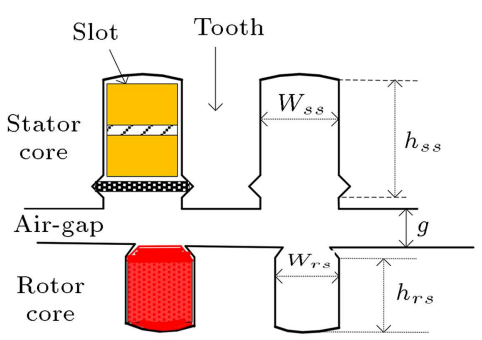

(b)

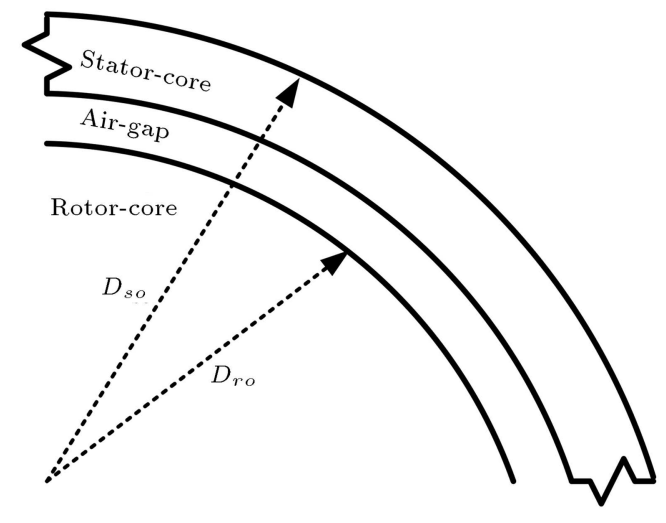

(c)

Figure 3. (a) Stator slot structure for high-power induction machine. (b) Configuration of stator and rotor slots. (c) Overall dimensions.

$l_{f e}$ stack length, $D_{a g}$ air-gap average diameter, $\varphi_{m}$ maximum flux per pole, and $p$ number of pole pairs.

The motor air-gap length is dependent on the overall dimensions and is determined using Eq. (5) [1921]:

$$
g=0.2+2 *\left(l_{f e} D_{a g}\right)^{0.5} .
$$

The number of stator slots is obtained using Eq. (6):

$$
Q_{s}=m p(2+k) \text {, }
$$

where $k$ is an even integer for symmetrical winding and an odd integer for unsymmetrical winding; $m$ and $p$ are the number of phases and pole-pairs, respectively.

Minimum air-gap length, ratio of pole pitch length to the minimum air-gap length, power factor, and efficiency were affected by selection of machine pole numbers. In this study, there are 4 poles equal to all the mentioned items. The value of $k$ is set to 2 and the number of motor slots is obtained as 56 considering the intended motor characteristics. The machine 
Table 1. The meaning of the symbols used in Figure 3.

\begin{tabular}{cl}
\hline Symbol & \multicolumn{1}{c}{ Description } \\
\hline$h_{s s}$ & Stator slot height \\
$w_{s s}$ & Stator slot width \\
$h_{\text {ins }}$ & Inter layer insulation \\
$h_{1}$ & One conductor layer height \\
$h_{2}$ & Top layer insulation + wedge height \\
$h_{3}$ & Top lining height \\
$h_{r s}$ & Rotor slot height \\
$w_{r s}$ & Rotor slot width \\
$g$ & Air gap length \\
$D_{s o}$ & Stator outer diameter \\
$D_{r o}$ & Rotor outer diameter \\
\hline
\end{tabular}

structure is different for high- and low-output powers. For example, the coils are insulated regarding the voltage level, stator slots are open, and the conductor is stranded with square cross-section and cooling ducts are employed in rotor and stator in the case of highrated power machines.

In order to calculate the cross-section of stator conductors, the motor rated current should be calculated first and then, the cross-section can be obtained based on permissible current density and table of available strands specifications.

The current flowing through motor winding is obtained as follows:

$$
\begin{aligned}
& \mathrm{I}_{p h}=\frac{S_{n}}{V_{l} * m}(A), \\
& S_{n}=\frac{P_{n}}{\eta_{n} \times P F_{n}}, \\
& S=\frac{I_{p h}}{\mathrm{~J}_{s} \mathrm{a}_{s} \mathrm{a}_{i}}\left(\mathrm{~mm}^{2}\right),
\end{aligned}
$$

where $S_{n}$ and $P_{n}$ are the rated apparent power and active power, respectively, $\eta_{n}$ and $P F_{n}$ denote nominal efficiency and power-factor, respectively, $V_{l}$ is the rated phase-to-neutral voltage, $J_{s}$ is the permissible current density, $a_{s}$ is the number of strands per turn, and $a_{i}$ is the number of parallel branches in winding. According to the required cross-section and considering the available standard conductors, the standard dimensions are selected.

The number of coil turns, $N_{t}$, is determined using Eqs. (10)-(12) [20,21]:

$$
\begin{aligned}
& V_{p h}=\varphi_{p} N_{p h} K_{w}(2 \pi f), \\
& N_{t}=N_{p h} a_{i} /(2 . p . q), \\
& \varphi_{p}=\frac{B_{g} D_{a g} l_{f e} \pi}{2 p}
\end{aligned}
$$

where $B_{g}$ is the average flux density in the air-gap region, $(2 / \pi) \times B_{m}, L$ is the core length, $D_{a g}$ is the air-gap average diameter, $p$ is the number of pair-poles, $q$ is the number of pole slots at each phase, $N_{t}$ is the number of series loops in a coil, and $a_{i}$ denotes the number of parallel paths.

Another important point in the design of the induction motor is electromagnetic utilization, which is dependent on the overall dimensions, speed, and power. The value of $C$ is calculated as follows:

$$
C=\frac{S_{a g}}{n_{s} D^{2} L}=\sqrt{2} \pi k_{w} \cdot A_{s} \cdot B_{a g},
$$

where $S_{a g}$ is the internal apparent power which is almost $96 \%$ of $S_{n}$ in the case of 4-pole induction motor and $A_{s}$ is the electric loading in $A / m$ [20].

By assigning reasonable values based on production experience to $\eta_{n}, P F_{n}, D_{a g}, l_{f e}, g, A_{s}$, and $B_{a g}$, stator core and winding can be designed.

Rotor is one of the important parts of an induction motor and the mechanical and electrical considerations should be taken into account in its design process. The number of rotor and stator slots should not be equal so as to avoid the cogging torque effect. In addition, in order to minimize the inter-bar currents, the difference between the rotor and stator slots should not exceed $20 \%$. To minimize the acoustic noise, the difference between the number of rotor and stator slots should satisfy the following criterion $[18,20]$ :

$$
\begin{gathered}
\left|Q_{s}-Q_{s}\right| \neq 0,1,2, \ldots, r *, 2 p, 2 p \mp 1,2 p \mp 2, \\
2 p \mp 3, \ldots, 2 p \mp r *
\end{gathered}
$$

where $r^{*}$ is an integer number. Another important point that should be considered in rotor design is the radial force. In order to reduce this force, the number of rotor slots should be even. The flux pulsation in teeth should be minimized to reduce the additional losses; thus, the rotor to stator slot number ratio should not below 0.8 or above 1.2 ; otherwise, slot frequent flux pulsation is too big [20].

Since the machine is a high-power motor, both radial and axial cooling channels may be incorporated into the stator and rotor cores. The presence of radial air ducts causes distortion in the flux density distribution along the axial length. To obtain the flux density distribution with acceptable distortion and modify the Carter coefficient relationships for modifying the average flux density, the number and width of radial air channels are obtained according to Eqs. (15) and (16), respectively. In addition, since the presence of axial ducts reduces the effective yoke thickness and increases the flux density and core loss in these regions, the diameter of these channels is usually designed to be $25 \%$ of the yoke thickness. These channels are usually in the middle of the yoke and studies have shown that 
Table 2. The nominal values used to the design 7-phase induction motor.

\begin{tabular}{lccccc}
\hline Description & Notation & Value & Description & Notation & Value \\
\hline Phase number & $m$ & 7 & Poles numbers & $2 p$ & 2 \\
Rated voltage & $V_{p h}$ & $6000 \mathrm{v}$ & 6 & Stator connection & - \\
Power factor & $\cos _{\varphi}$ & 0.9 & 7 & Efficiency & $\eta$ \\
Mechanical power & $P$ & $1000 \mathrm{kw}$ & 8 & Rated frequency & $f$ \\
\hline
\end{tabular}

the number of rotor axial channels can be selected using Eq. (17):

$$
\begin{aligned}
& n_{r d}=\text { floor }\left(\frac{l_{f e}}{20 g}\right)-1, \\
& l_{r d}=0.2\left(\frac{l_{f e}}{n_{r d}+1}\right), \\
& n_{a d}=\text { floor }\left(\frac{\pi\left(D_{r i}+h_{r y}\right)}{D_{r d} * 1.75}\right),
\end{aligned}
$$

where $l_{f e}$ is the iron stack length, $D_{r i}$ the rotor inner diameter, $h_{r y}$ the rotor yoke thickness, and $D_{r d}$ diameter of rotor axial ducts.

The specifications used to design the intended induction motor are given in Table 2. The unknown values and parameters are calculated optimally using curves and tables based on accurate and practical constraints.

The limitations due to materials properties, construction, temperature rise, and those imposed by IEC standards were considered in this traditional design study. These limitations include the current density in coils, the flux density in cores-teeth and the yoke regions, the outer diameter to axial length ratio, and temperature rise $[20,21]$.

\section{WF of 7-phase induction motor}

The concept of WF is based on Magneto-Motive Force (MMF) wave. These waves are in accordance with stator rotational magnetic field and are measured by Ampere-Turn unit (AT). In fact, the WF at point $\theta_{s}$ is the sum of the phase conductors located within $\left[0, \theta_{s}\right]$ interval, which is calculated based on the assumption that the conductors with currents in a specified direction have positive MMF and those with currents in the opposite direction are assumed to have negative MMF. The magnetic driving force relation is as follows [22]:

$$
M M F\left(\theta_{s}, t\right)=\sum N_{n}\left(\theta_{s}\right) i_{n}(t)
$$

where $N_{n}\left(\theta_{s}\right)$ indicates number of turns carrying $i_{n}(t)$ current with the specified direction. The origin of angle axis should be selected in such a way as to have zero average value for MMF function. Also, the average value of the WF is equal to zero, since current conductors are equally arranged over the stator peripheral.

$$
\int_{0}^{2 \pi} N\left(\theta_{s}\right) d \theta_{s}=0 .
$$

WF method is used to calculate the synchronous and induction machines inductances, while the airgap length could be fixed or variable in these calculations [23,24].

Considering $n_{A}(\theta)$ as winding turn function, which is comprehensively explained in [23], WF can be written as Eq. (20) in the case of uniform air-gap:

$$
N_{A}(\theta)=n_{A}(\theta)-n_{A}(\theta),
$$

where $n_{A}(\theta)$ is the average of turn function.

The WF of one stator phase and one rotor loop of a 7-phase motor are shown in Figures 4 and 5, respectively.

The stator and rotor windings self and mutual inductances are calculated using their related WF.

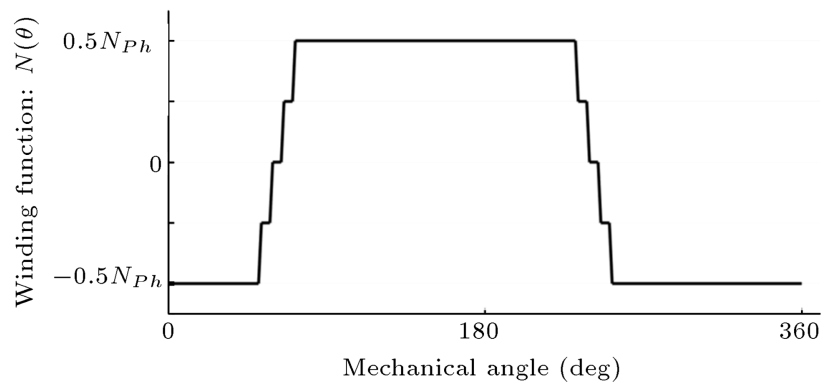

Figure 4. Winding function of one stator phase.

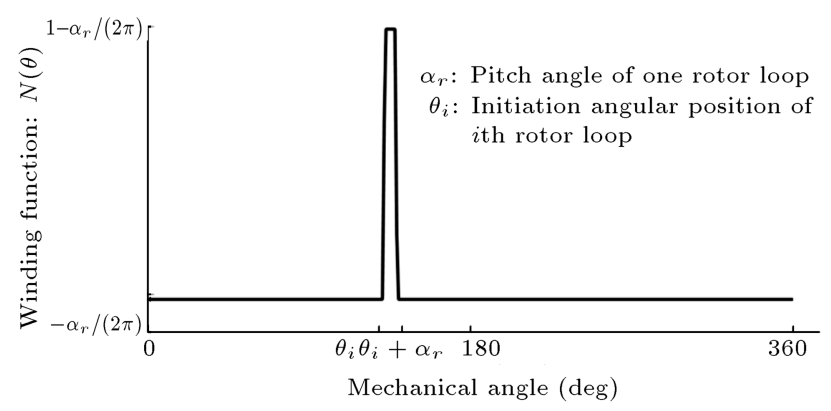

Figure 5. Winding function of one rotor loop. 
The stator of 7-phase induction motor consists of seven similar windings. These phase windings have self and mutual inductances that are calculated using Eqs. (21) and (22), respectively [23]:

$$
\begin{aligned}
L_{i j} & =0.5 \mu_{0} D_{a g} \ell_{f e} \int_{0}^{2 \pi} \frac{1}{g} n_{i}(\theta) N_{j}(\theta) d \theta, \\
L_{i j} & =\frac{Q_{s}{ }^{2} \pi 0.5 \mu_{0} D_{a g} \ell_{f e}}{54 p^{2} g}\left(\frac{3 p N_{t}}{Q_{s}}\right)^{2}, \quad i \# j, \\
L_{i i} & =\left(\frac{7 Q_{s}{ }^{2}}{54 p^{2}}+\frac{1}{9}\right) \frac{\pi 0.5 \mu_{0} D_{a g} \ell_{f e}}{g}\left(\frac{3 p N_{t}}{Q_{s}}\right)^{2} .
\end{aligned}
$$

The WF of the squirrel cage rotor loops and the stator phase winding are presented previously. Accordingly, the mutual inductance between $i$ th stator windings and $j$ th rotor loops can be obtained using Eq. (23) [23]:

$$
L_{i j}=0.5 \mu_{0} D_{a g} \ell_{f e} \int_{0}^{2 \pi} \frac{1}{g} n_{j}(\theta) N_{i}(\theta) d \theta .
$$

\section{Coupled-circuit model of seven-phase induction motor}

The 7-phase induction motor, which is fed by sinusoidal voltage source, has a very complex equivalent circuit model due to the self and mutual inductances between the stator and rotor coils. Park transform is used to convert time domain voltage equations into $d q$-axis coordinate. There is $\frac{2 \pi}{7}$ phase difference among the seven voltage sources applied to the stator windings [25].

$$
\begin{aligned}
& V_{s p}=R_{s} i_{s p}+j w_{p} \varphi_{s p}+\frac{d \varphi_{s p}}{d t} \quad p=1,3,5, \\
& O=R_{R p} i_{R p}+j\left(w_{p}-p w_{m}\right) \varphi_{R R}+\frac{d \varphi_{R p}}{d t} \\
& \quad p=1,3,5, \\
& \varphi_{s p}=L_{s p} i_{s p}+M_{p} i_{R p} \quad p=1,3,5, \\
& \varphi_{s p}=M_{p} i_{s p}+L_{R p} i_{R p} \quad p=1,3,5, \\
& T=\frac{N}{2} P \sum_{p=1.2 .3} P M_{p} i_{s p} . j i_{R p} .
\end{aligned}
$$

The rotor and stator voltage equations in $d q$-domain could be written as Eqs. (29) and (30), respectively, assuming that the machine equations are transferred to the reference frame at the desired angular velocity of $\omega_{e}$ :

$$
\begin{aligned}
& V_{d s}=R_{s} i_{d s}+\frac{d}{d t} \omega_{d s}-\omega_{e} \psi_{q s}, \\
& V_{q s}=R_{s} i_{q s}+\frac{d}{d t} \omega_{q s}+\omega_{e} \psi_{d s}, \\
& V_{d r}=R_{r} i_{d r}+\frac{d}{d t} \psi_{d r}-\left(\omega_{e}-\omega_{r}\right) \psi_{q r}, \\
& V_{q r}=R_{r} i_{q r}+\frac{d}{d t} \psi_{q r}+\left(\omega_{e}-\omega_{r}\right) \psi_{d r} .
\end{aligned}
$$

The above equations are written using the Park transform for the 7-phase system. The transformation matrix is as Eq. (31) [26] as shown in Box I, where $\alpha$ is equal to $\frac{2 \pi}{7}$.

Using analytical procedures reported for the 3phase induction machine, the dq relations of stator and rotor currents are obtained through Eqs. (32) and (33), respectively:

$$
\begin{aligned}
& i_{d s}=\frac{\psi_{d s}\left(L_{q r}+L_{m}\right)-L_{m} \psi_{d r}}{L_{l r} L_{L r}+L_{l s} L_{m}+L_{r r}+L_{m}}, \\
& i_{q s}=\frac{\psi_{q s}\left(L_{l r}+L_{m}\right)-L_{m} \psi_{q r}}{L_{l r} L_{L r}+L_{l s} L_{m}+L_{r r}+L_{m}}, \\
& i_{d r}=\frac{\psi_{d r}\left(L_{l s}+L_{m}\right)-L_{m} \psi_{d s}}{L_{l r} L_{L r}+L_{l s} L_{m}+L_{r r}+L_{m}}, \\
& i_{q s}=\frac{\psi_{q r}\left(L_{l s}+L_{m}\right)-L_{m} \psi_{q s}}{L_{l r} L_{L r}+L_{l s} L_{m}+L_{r r}+L_{m}} .
\end{aligned}
$$

Rotor speed is obtained using mechanical dynamic equation:

$$
\begin{aligned}
\omega_{r} & =\int \frac{P}{2 j}\left(T_{e}-T_{L}\right) d t, \\
T_{e} & =P L_{m}\left(i_{q r} i_{d r}-i_{d s} i_{q r}\right) .
\end{aligned}
$$

$\left[\begin{array}{l}V_{q} \\ V_{d} \\ V_{q 1} \\ V_{d 1} \\ V_{q 2} \\ V_{d 2} \\ V_{0}\end{array}\right]=\left[\begin{array}{lllllll}1 & \cos \alpha & \cos 2 \alpha & \cos 3 \alpha & \cos 4 \alpha & \cos 5 \alpha & \cos 6 \alpha \\ 0 & \sin \alpha & \sin 2 \alpha & \sin 3 \alpha & \sin 4 \alpha & \sin 5 \alpha & \sin 6 \alpha \\ 1 & \cos \alpha & \cos 2 \alpha & \cos 3 \alpha & \cos 4 \alpha & \cos 5 \alpha & \cos 6 \alpha \\ 0 & \sin \alpha & \sin 2 \alpha & \sin 3 \alpha & \sin 4 \alpha & \sin 5 \alpha & \sin 6 \alpha \\ 1 & \cos \alpha & \cos 2 \alpha & \cos 3 \alpha & \cos 4 & \cos 5 & \cos 6 \alpha \\ 0 & \sin \alpha & \sin 2 \alpha & \sin 3 \alpha & \sin 4 \alpha & \sin 5 \alpha & \sin 6 \alpha \\ \sqrt{2 / 7} & \sqrt{2 / 7} & \sqrt{2 / 7} & \sqrt{2 / 7} & \sqrt{2 / 7} & \sqrt{2 / 7} & \sqrt{2 / 7}\end{array}\right]$




\section{Lumped-parameter thermal model}

In the development process of electric machines design, thermal limitations have always been a key factor affecting the power to volume density, since the manufacturers always aim to fabricate machines with lower dimensions and less weight of active materials. Therefore, processing power at lower volume and dimensions increases the temperature in different parts. According to the Arrhenius law, the insulators' chemical decay procedure increases exponentially as temperature increases. According to Mottisiger rule, a 10-degree increase in temperature decreases the lifespan by half, approximately. Therefore, the thermal analysis of electrical machines is of great importance. Various thermal models have been developed for machine design and analysis studies, each having its own advantages and disadvantages [27-30]. In order to perform an optimized design with the aim of employing maximum capacities of the active materials and ensure the desired thermal lifetime, a thermal model with low error-margin should be used in optimization and design process to ensure limited temperature values according to the insulation and thermal classes. The current approach aims to simultaneously use electromagnetic and thermal models to achieve designs that meet the exact customer requirements.

The insulation materials used in electrical machines are divided into different thermal and insulation classes according to IEC60085 standard. According to this standard, the intended motor insulation class is $\mathrm{F}$ and the thermal class is $\mathrm{B}$. The electrical machine cooling system has an IC code according to IEC60034-6.

Heat is transmitted by three methods including conduction, convection, and radiation. Given that the body of the electric machines is kept at a low temperature, there is no radiation heat transfer and the heat is transferred using convection and conduction methods. Each part that performs heat transfer is modeled using a thermal resistor and the parts that generate heat are modeled as thermal sources. The thermal resistance in the conduction method is obtained using Eq. (36):

$$
R_{T h}=\frac{l}{A \lambda_{T h}},
$$

where $\lambda_{T h}$ is thermal conductivity, $\lambda$ is cross-section area, and $l$ is the length of material. The thermal resistance in the convection method is related to the heat transfer coefficient and cross-section area and is obtained using Eq. (37):

$$
R_{T h}=\frac{l}{A \alpha} .
$$

Heat transfer coefficient $(\alpha)$ is a function of cooling fluid velocity and path type as obtained using Table 3 .
Table 3. Thermal conductivity of different types of air and materials in electrical machines (convection method) [28].

\begin{tabular}{lc}
\hline \multicolumn{1}{c}{ Type of cooling air } & $\boldsymbol{\alpha}\left(\frac{\mathrm{w}}{\mathbf{m}^{2} \mathrm{k}^{0}}\right), \boldsymbol{v}\left(\frac{\mathrm{m}}{\mathrm{s}}\right)$ \\
\hline Nearly not moving air & 8 \\
$v=[0-0.5 \mathrm{~m} / \mathrm{s}]$ & \\
Moving air - Flat hot metal surface & $\alpha=15 \mathrm{v}^{2 / 3}$ \\
Moving air - Insulated winding & $\alpha=8 \mathrm{v}^{3 / 4}$ \\
\hline
\end{tabular}

Table 4. Density and heat capacity of different materials used in electrical machines [29].

\begin{tabular}{lcc}
\hline Material & $\boldsymbol{C}\left(\mathbf{W} /\left(\mathbf{k g} \cdot \mathbf{k}^{\circ}\right)\right.$ & $\boldsymbol{\gamma}\left(\mathbf{k g} / \mathbf{m}^{\mathbf{3}}\right)$ \\
\hline Air at constant & 1009 & 1.229 at $25^{\circ} \mathrm{C}$ \\
pressure & 388.5 & 8900 \\
Copper & 502 & 7850 \\
Iron & $1320-1450$ & 1500 \\
Epoxy resin & &
\end{tabular}

Another important point that should be considered in modeling is the thermal energy storage which is similar to the capacitors in electrical circuits. The joule amount of stored heat is obtained from Eq. (38):

$$
W_{T h}=\gamma \Delta \vartheta C V
$$

where $C$ denotes the specific heat capacity and $\gamma$ represents the body mass density, which are calculated using Table 4 .

Heat is generated in machine due to the ohmic and iron loss and friction loss. The friction in the motor is divided into two parts: The bearing and the aerodynamic friction, which is a polynomial function of the motor speed.

Since two metals of iron and copper are incorporated in induction machine structure, the thermal variation equation governing the machine is supposed to be a second-order differential equation. The temperature rise is calculated as follows [29,30]:

$$
\begin{gathered}
\Delta \vartheta_{c u}(t)=\frac{1}{\sqrt{\left(\frac{1}{\tau}+\frac{1}{\tau_{c u}}\right)^{2}-\frac{4}{\tau_{c u} \tau_{F e}}}} \\
\cdot\left(\left[\left(\frac{P_{c u, s}}{m_{c u} c_{c u}}+\frac{\Delta \vartheta_{c u \infty}}{T_{\vartheta 2}}\right)\right.\right. \\
\left.\left.\cdot e^{-\frac{t}{T \vartheta_{1}}}-\left(\left(\frac{P_{c u, s}}{m_{c u} c_{c u}}+\frac{\Delta \vartheta_{c u}}{T_{\vartheta_{1}}}\right) \cdot e^{-\frac{t}{T \vartheta_{2}}}\right)\right]\right),
\end{gathered}
$$

$$
\Delta \vartheta_{f e}(t)=\frac{1}{\sqrt{\left(\frac{1}{\tau}+\frac{1}{\tau_{c u}}\right)^{2}-\frac{4}{\tau_{c u} \tau_{F e}}}}
$$




$$
\begin{gathered}
\cdot\left[\left(\frac{P_{f e, s}}{m_{f e} c_{f e}}+\frac{\Delta \vartheta_{f e \infty}}{T_{\vartheta 2}}\right)\right. \\
\left.\cdot e^{-\frac{t}{T \vartheta_{1}}}-\left(\left(\frac{P_{f e, s}}{m_{f e} c_{f e}}+\frac{\Delta \vartheta_{c u \infty}}{T_{\vartheta 1}}\right) \cdot e^{-\frac{t}{T \vartheta^{2}}}\right)\right] \\
\tau_{c u}=m_{c u} c_{c u} R_{t h 2}, \\
\tau_{F e}=m_{F e} c_{F e} R_{t h 1}, \\
\tau=m_{F e} c_{F e} \frac{R_{t h 1} * R_{t h 2}}{R_{t h 1}+R_{t h 2}}, \\
T \vartheta_{1}=\frac{2}{\frac{1}{\tau}+\frac{1}{\tau_{c u}}-\sqrt{\left(\frac{1}{\tau}+\frac{1}{\tau_{c u}}\right)^{2}-\frac{4}{\tau_{c u} \tau_{F e}}}} \\
T \vartheta_{2}=\frac{2}{\frac{1}{\tau}+\frac{1}{\tau_{c u}}-\sqrt{\left(\frac{1}{\tau}+\frac{1}{\tau_{c u}}\right)^{2}-\frac{4}{\tau_{c u} \tau_{F e}}}} .
\end{gathered}
$$

It is assumed that there is no peripheral heat transfer between two adjacent stator slots and two adjacent rotor slots in the lumped parameter thermal model. It is worth to notice that in this model it is enough to model only one stator slot and one rotor slot and then, by modifying the loss sources concerned with rotor slots, the models of other slot are obtained and connected to each other. In the following, the equivalent circuits of the stator and rotor slots are obtained.

\subsection{Thermal equivalent model for one step of stator slot}

Figure 6 shows a stator slot pitch along with its

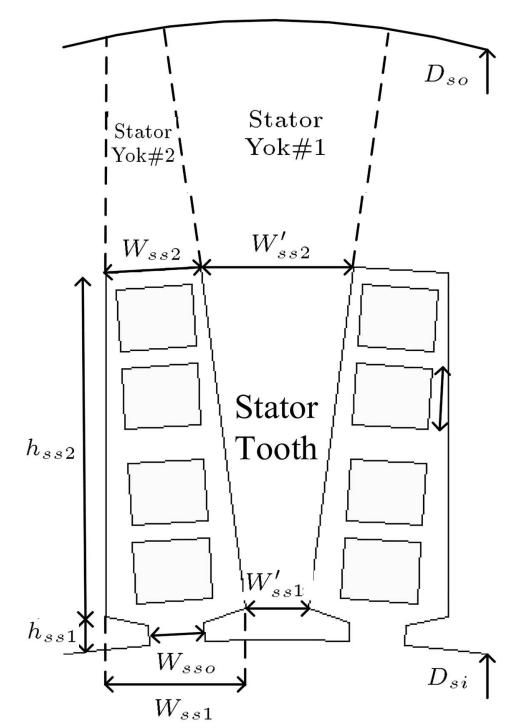

Figure 6. Geometry and dimensions of one stator slot pitch for lumped-parameter thermal model. dimensioning notations. The loss sources in this area are as follows:

Ohmic loss inside the slot:

$$
\begin{aligned}
P_{c u}^{1 s}= & P_{c u} / N_{s s} \\
& \frac{l}{l+2 \pi\left(D_{s i}+2 h_{s s}+2 h_{c w}+h_{p w}\right) / N_{s s}} \frac{\tau_{s s}}{\pi D_{s i}}
\end{aligned}
$$

Ohmic loss of end-windings:

$$
\begin{aligned}
P_{c u}^{1 e w} & =P_{c u, p w} / N_{s s} \\
& \frac{2 \pi\left(D_{s i}+2 h_{s s 1}+2 h_{c w}+h_{p w}\right) / N_{s s}}{l+2 \pi\left(D_{s i}+2 h_{s s}+2 h_{c w}+h_{p w}\right) / N_{s s}} \frac{\tau_{s s}}{\pi D_{s i}}
\end{aligned}
$$

Iron loss of tooth area:

$$
P_{f e}^{s t},
$$

Iron loss of yoke area (above the tooth):

$$
P_{f e}^{s y_{1}}
$$

Iron loss of yoke area (above the slot):

$$
P_{f e}^{s y_{2}} \text {. }
$$

Lumped parameter thermal circuit of one stator slot pitch is shown in Figure 7. The definitions of thermal resistances presented in this figure are also given in Table 5 .

\subsection{Thermal equivalent model for one rotor slot pitch}

The current amplitudes are equal in rotor bars, but flux densities in tooth and yoke areas are different, so the temperature distribution in rotor is uneven to some extent. In this study this problem is ignored for the sake of simplicity and it is assumed that the temperature distribution in each radial section of the rotor core is similar to the other parts. The thermal network is plotted in Figure 8 for one rotor slot pitch. The definitions of thermal resistances presented in this figure are also given in Table 6 .

By investigating the fabricated machines' cooling systems, it is found that only radial channels are involved. In this case, the only change that should be made to the lumped parameter thermal circuit is to replace the core length with $l_{f e} /\left(n_{r d}+1\right)$ in thermal resistance calculations $[31,32]$.

\section{Design optimization}

Electric machine design optimization is a multiobjective problem that involves different constraints and variables. First, optimization variables including magnetic, electric, and geometric parameters are 


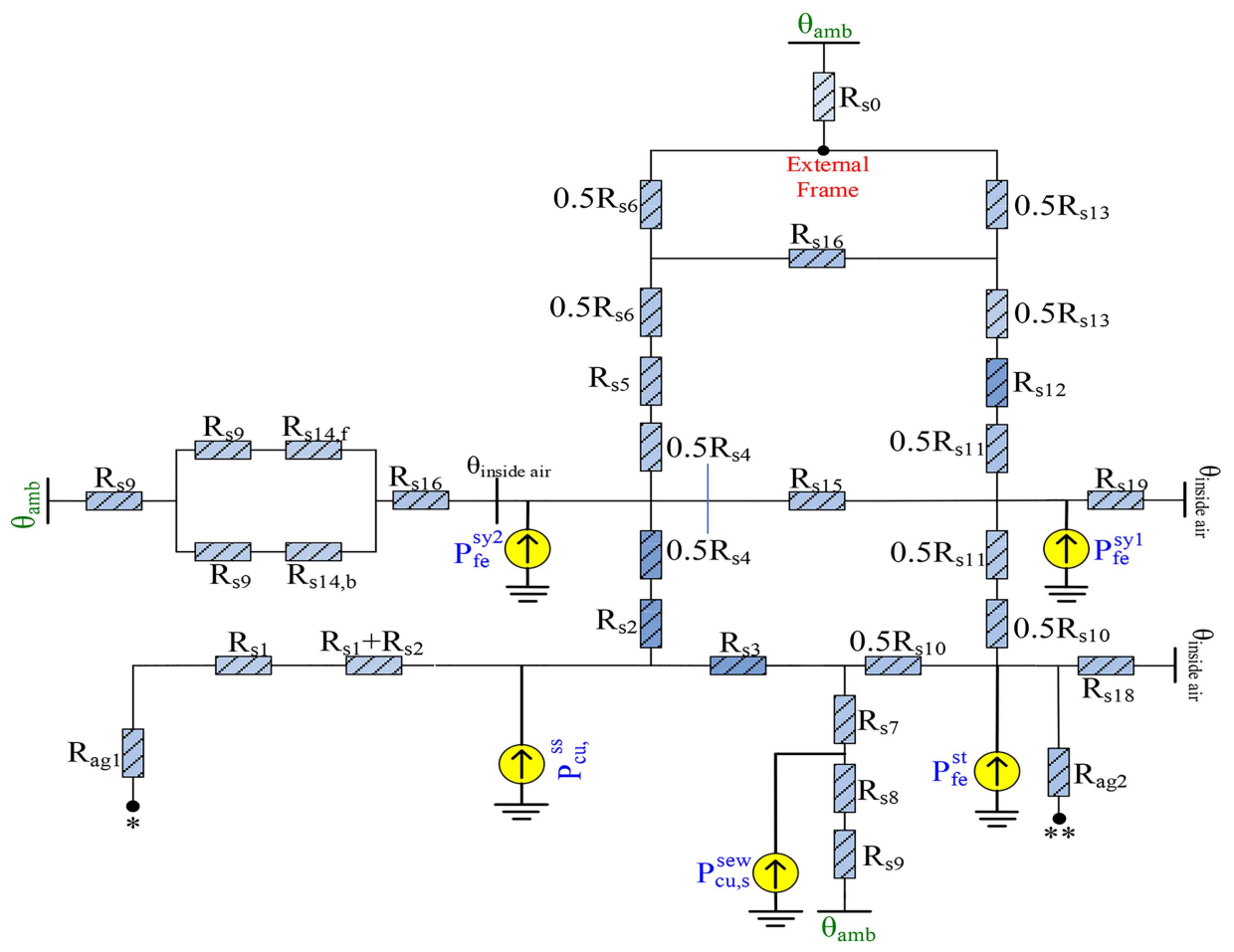

Figure 7. Lumped parameter thermal model for one stator slot pitch.

Table 5. Definitions of the thermal resistance shown in Figure 7.

\begin{tabular}{ll}
\hline & \\
\hline Rs0 & Radiative thermal resistance and convection between the outer frame and environment \\
Rs1 & Thermal conductive resistance of winding coils \\
Rs2 & Thermal conductive resistance of slot end \\
Rs3 & Thermal conductive resistance of slot insulator \\
Rs4, Rs11 & Thermal conductive resistance of stator yoke above the slot, above the teeth \\
Rs5, Rs12 & Thermal conductive resistance of air-gap between stator core and outer frame \\
Rs6, Rs13 & Thermal conductive resistance of outer frame, above the slot, above the teeth \\
Rs7 & Lateral thermal conductive resistance between winding ends to the core center \\
Rs8 & Convective thermal resistance between winding ends to the air inside the machine case \\
Rs9 & Thermal conductive resistance and convection between end caps and environment \\
Rs10 & Thermal conductive resistance of stator tooth \\
Rs14 & Thermal resistance of convection between stator core and the air inside the machine case \\
Rs15 & Thermal conductive resistance between two parts above the slot and above the stator \\
Rs16 & Thermal conductive resistance between two parts above the slot and above the external frame tooth \\
Rs17 & Thermal conductive resistance from core center to the core end \\
Rag1 & Thermal conductive resistance between stator and rotor slots through air-gap \\
Rag2 & Thermal conductive resistance between stator and rotor teeth through air-gap \\
\hline
\end{tabular}

chosen accurately based on their variation influences on analytical results. Then, objective functions and constraints are formulated using design variables and finally, a population-based optimization solver is used to obtain optimum values of design variables. In this paper, the optimization objectives include maximization of efficiency, power factor, power-to-weight ratio, and starting torque and minimization of starting current and fabrication cost. As a result, the objective function is defined as Eq. (45):

$$
O F(x)=\frac{\left(\frac{P_{\text {out }}}{\text { weight }}\right)^{k_{1}} \eta^{k_{2}} P F^{k_{3}} T_{s t}^{k_{4}}}{I_{s t}^{k_{5}}}
$$


Table 6. Definition of the rotor network thermal resistors.

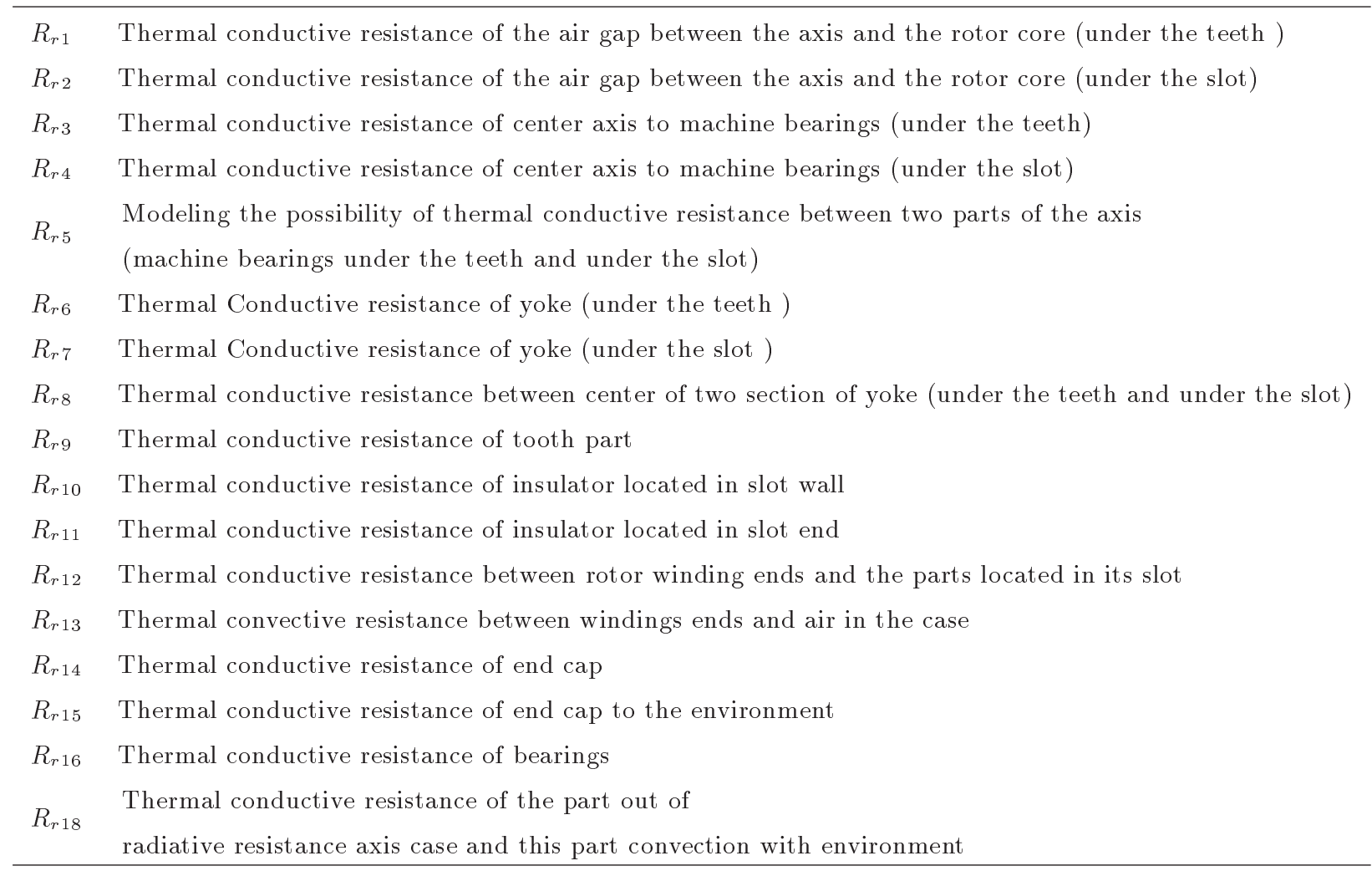

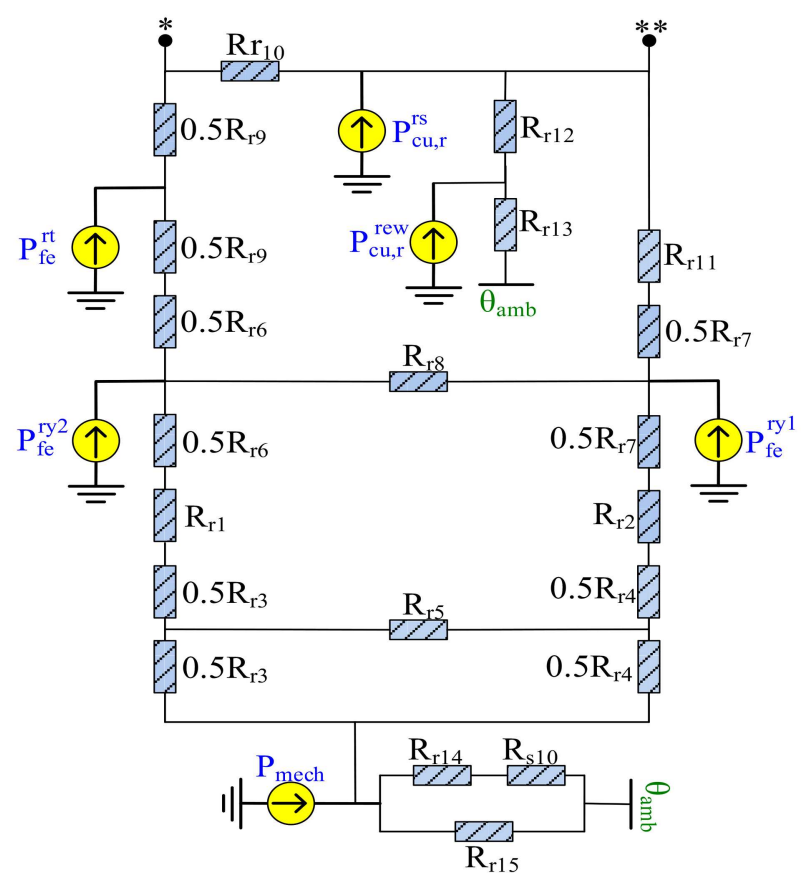

Figure 8. The complete thermal model of a 7-phase motor.

The optimization variables are shown in Table 7 .

The optimization flowchart is illustrated in Figure 9 . The boundary values and inequality constraints are listed in Table 8. Genetic algorithm has been used as an optimization solver and the optimization flowchart is coded in MATLAB software environment.

The population-based optimal design procedure can be performed using the derived analytical model of acceptable accuracy and short computation time. The optimized design parameters are given in Tables 9-11.

The values of the important quantities of the machine designed using traditional and proposed optimal procedures are compared in Table 12. It can be seen that the optimally designed motor shows considerably better performance features than the machine designed by traditional design approach.

\section{2D FE analyses}

As discussed in the previous sections, the coupledcircuit model of the 7-phase induction motor is established in MATLAB/Simulink software. The 7-phase power supply is simulated using a 7-phase inverter with IGBT switches. To verify the accuracy of the coupled-circuit model, its results were compared with the results of $2 \mathrm{D}$ time-stepping finite element analyses. It should be noted that 2D-FE analyses are done using Ansys Maxwell R19 software. The FE simulation results of rotating speed, electromagnetic torque, stator currents, rotor bar current, airgap flux density waveform, and $2 \mathrm{D}$ view of flux density distribution are shown in Figures (10)-(15), respectively. The studies reveal good performance of 
Table 7. Optimization variables.

\begin{tabular}{|c|c|c|c|}
\hline Parameter & Description & $\begin{array}{l}\text { Variable } \\
\text { symbol }\end{array}$ & $\begin{array}{l}\text { Boundaries } \\
\text { [Min.Max.] }\end{array}$ \\
\hline$D_{a g}$ & Air-gap average diameter & $X_{1}$ & {$[300 \mathrm{~mm} 600 \mathrm{~mm}]$} \\
\hline$l_{f e}$ & Stack length & $X_{2}$ & [200 mm $1000 \mathrm{~mm}]$ \\
\hline$w_{s s t}$ & Stator slot teeth width & $X_{3}$ & {$[8 \mathrm{~mm} 38 \mathrm{~mm}]$} \\
\hline$h_{s s}$ & Stator slot height & $X_{4}$ & {$[30 \mathrm{~mm} 150 \mathrm{~mm}]$} \\
\hline$h_{s y}$ & Stator yoke thickness & $X_{5}$ & {$[30 \mathrm{~mm} 150 \mathrm{~mm}]$} \\
\hline$N_{s s}$ & Stator winding turn number & $X_{6}$ & {$\left[\begin{array}{ll}14 & 224\end{array}\right]$} \\
\hline$g$ & Air gap physical length & $X_{7}$ & {$[1 \mathrm{~mm} 10 \mathrm{~mm}]$} \\
\hline$w_{r s t}$ & Rotor slot mouth width & $X_{8}$ & {$[5 \mathrm{~mm} 35 \mathrm{~mm}]$} \\
\hline$\alpha_{r s}$ & Rotor slot pitch angle & $X_{9}$ & {$[120] \times 180 / \pi$} \\
\hline$h_{r s}$ & Rotor slot height & $X_{10}$ & {$[20 \mathrm{~mm} 120 \mathrm{~mm}]$} \\
\hline$h_{r y}$ & Rotor yoke thickness & $X_{11}$ & {$[20 \mathrm{~mm} 200 \mathrm{~mm}]$} \\
\hline$w_{r e r}$ & Rotor end ring width & $X_{12}$ & [30 mm $130 \mathrm{~mm}]$ \\
\hline
\end{tabular}

Table 8. Constraints used in optimization process.

\begin{tabular}{|c|c|c|c|c|c|}
\hline Value & Description & Symbol & Value & Description & Symbol \\
\hline$F_{f} \leq\left(b_{7 \text { ref }}=0.42\right)$ & Stator slot filling factor & $F_{f}$ & $s \leq\left(b_{1 \text { ref }}=0.05\right)$ & Rated slip & $s$ \\
\hline$I_{s t} / I_{n} \leq\left(b_{8 \text { ref }}=7\right)$ & Rated startup current & $I_{s t} / I_{n}$ & $B_{s y} \leq\left(b_{2 r e f}=1.5 \mathrm{~T}\right)$ & Stator yoke flux density & $B_{s y}$ \\
\hline $\cos \varphi \geq\left(b_{9 \text { ref }}=0.85\right)$ & Power factor & $\cos \varphi$ & $B_{r y} \leq\left(b_{3 r e f}=1.4 \mathrm{~T}\right)$ & Rotor yoke flux density & $B_{r y}$ \\
\hline$T_{m} / T_{n} \geq\left(b_{10 \text { ref }}=2.5\right)$ & Maximum torque to rated torque & $T_{m} / T_{n}$ & $B_{s t} \leq\left(b_{4 r e f}=1.8 \mathrm{~T}\right)$ & Stator tooth flux density & $B_{s t}$ \\
\hline$\eta \geq\left(b_{11 \text { ref }}=0.9\right)$ & Efficiency & $\eta$ & $B_{r t} \leq\left(b_{5 r e f}=1.9 \mathrm{~T}\right)$ & Rotor tooth flux density & $B_{r t}$ \\
\hline$\vartheta \leq\left(b_{12 \text { ref }}=120^{\circ} \mathrm{C}\right)$ & Allowed temperature & $\vartheta$ & $T_{s} / T_{n} \geq\left(b_{6 r e f}=0.7\right)$ & Startup torque to rated torque & $T_{s} / T_{n}$ \\
\hline
\end{tabular}

Table 9. Specifications of stator core and winding of the optimum designed 7-phase induction motor.

\begin{tabular}{clcl}
\hline Quantity & \multicolumn{1}{c}{ Description } & Quantity & \multicolumn{1}{c}{ Description } \\
\hline 455 & Inner diameter $(\mathrm{mm})$ & $9 \times 1.5$ & Bare strip (width $\times$ thickness) (mm) \\
883 & Gross length $(\mathrm{mm})$ & 1 & Number of strands per conductor \\
755 & Net iron length $(\mathrm{mm})$ & 40 & Number of conductors per slot \\
3.2 & Inter-layer insulator thickness $(\mathrm{mm})$ & 5.4 & Current density $\left(\mathrm{A} / \mathrm{mm}^{2}\right)$ \\
3.03 & Thickness of coil insulation $(\mathrm{mm})$ & 12.6 & Slot-width $(\mathrm{mm})$ \\
M400-50A & Lamination material & 87.6 & Slot- height $(\mathrm{mm})$ \\
160 & Turns per phase (Turn) & 10 & Coil pitch (slots) \\
400 & Frame size (mm) & 5 & Wedge thickness (mm) \\
25.5 & Slot-pitch (mm) & 750 & Outer diameter (mm) \\
2.5 & Air-gap length $(\mathrm{mm})$ & 56 & Number of slots \\
8 & Width of radial ventilation ducts (mm) & 16 & Number of radial ventilation ducts \\
\hline
\end{tabular}




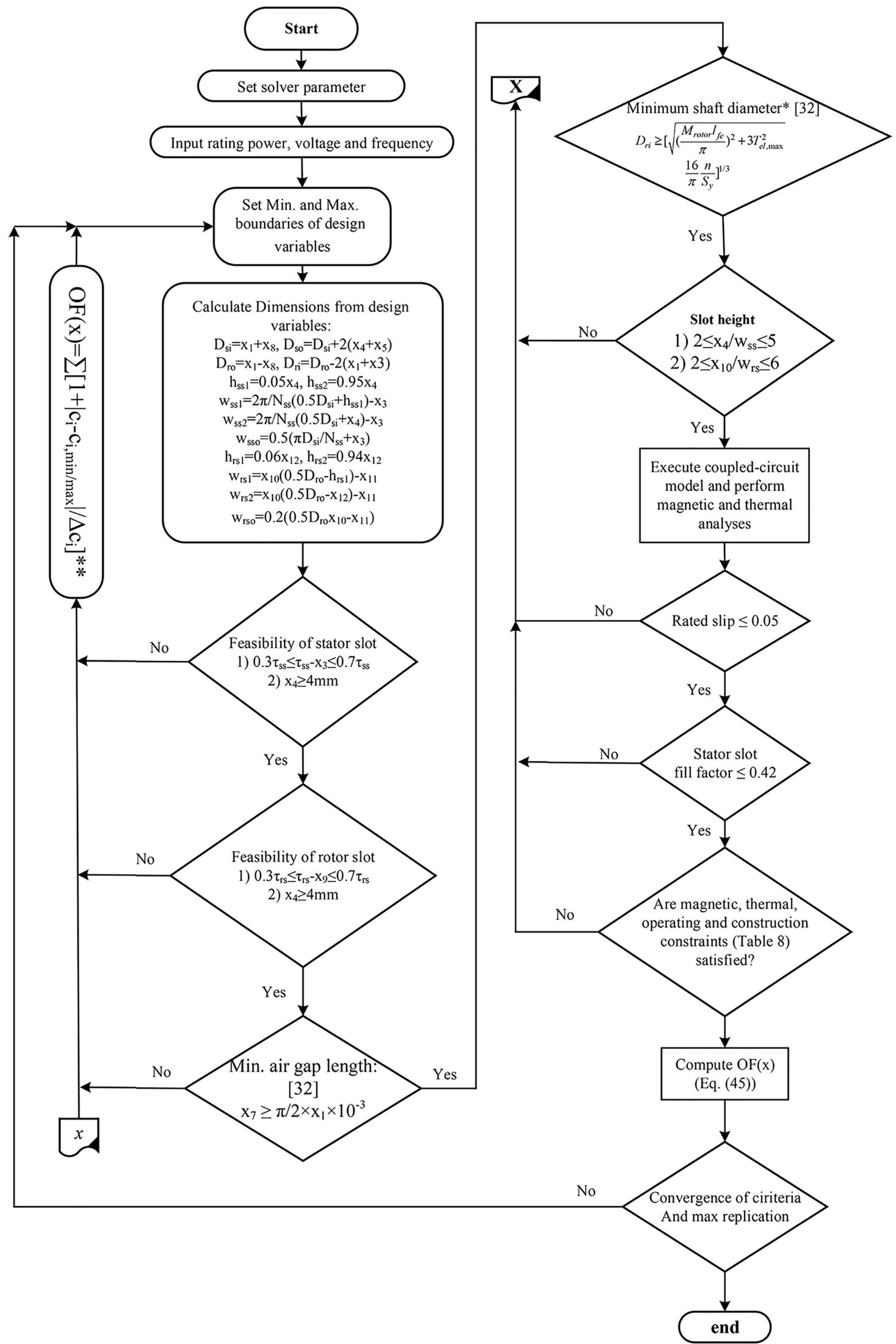

Figure 9. Flowchart of 7 -phase induction machine design procedure $\left({ }^{*} S_{y}\right.$ is yield strength $(190 \mathrm{MPa}$ for stainless steel at $\left.50^{\circ} \mathrm{C}\right) n \geq 1$ is safety factor, and ${ }^{* *} \Delta_{c_{i}}$ is set at 0.1 times maximum or minimum bound of the $c_{i}$ th constraints $\left(0.1 c_{i}\right.$, maxmin)) 
Table 10. Specifications of rotor core and cage winding of the optimum designed 7-phase induction motor.

\begin{tabular}{|c|c|c|c|}
\hline Quantity & Description & Quantity & Description \\
\hline Rotor slot dimension (width $\times$ height) $(\mathrm{mm})$ & $10.4 \times 58.6$ & Gap from slot mouth to bar conductor (mm) & 2.2 \\
\hline Length of bar (mm) & 901 & Outer diameter $(\mathrm{mm})$ & 450 \\
\hline end ring (width $\times$ thickness $)\left(\mathrm{mm}^{2}\right)$ & $73 \times 38$ & Rotor slot-pitch (mm) & 31.74 \\
\hline Rotor copper loss (W) & 9638.2 & Rotor bar current (A) & 441.9 \\
\hline Equivalent rotor resistor (ohm) & 0.986 & Inner diameter $(\mathrm{mm})$ & 150 \\
\hline Bar dimension (width $\times$ height) $(\mathrm{mm})$ & $10 \times 56$ & End-ring outer diameter (mm) & 968 \\
\hline Shaft diameter (mm) & 150 & End-ring inner diameter (mm) & 778 \\
\hline Number of slots & 48 & Width of radial ventilation ducts $(\mathrm{mm})$ & 10 \\
\hline Number of radial ventilation ducts & 15 & Slot mouth width (mm) & 5 \\
\hline Rotor bars and end-rings material & CuZn10 & Diameter of axial ducts (mm) & 25 \\
\hline Number of axial ducts & 15 & Diameter of axis of axial holes (mm) & 215 \\
\hline
\end{tabular}

Table 11. Loss and weight of different parts of the optimum designed 7-phase induction motor.

\begin{tabular}{clcl}
\hline Optimum quantity & \multicolumn{1}{c}{ Description } & Optimum quantity & \multicolumn{1}{c}{ Description } \\
\hline 358.3 & Weight of stator teeth $(\mathrm{kg})$ & 2571.9 & Iron loss of teeth $(\mathrm{W})$ \\
763.2 & Weight of stator yoke $(\mathrm{kg})$ & 10634.9 & Iron loss of yoke $(\mathrm{W})$ \\
1121.5 & Weight of stator iron $(\mathrm{kg})$ & 13206.8 & Total iron loss $(\mathrm{W})$ \\
805.8 & Weight of stator $(\mathrm{kg})$ & 16233.6 & Stator copper loss $(\mathrm{W})$ \\
\hline
\end{tabular}

Table 12. Comparison of important quantities of the machine designed using traditional and proposed optimal design approaches.

\begin{tabular}{cclccl}
\hline $\begin{array}{c}\text { Optimized } \\
\text { design }\end{array}$ & $\begin{array}{c}\text { Traditional } \\
\text { design }\end{array}$ & \multicolumn{1}{c}{ Description } & $\begin{array}{c}\text { Optimal } \\
\text { design }\end{array}$ & $\begin{array}{c}\text { Traditional } \\
\text { design }\end{array}$ & Description \\
\hline 2500 & 2453 & Weight (kg) & 0.9 & 0.85 & Power factor \\
5.1 & 6.3 & Starting current (p.u.) & 0.97 & 0.93 & Efficiency \\
1.33 & 1.43 & Stator Yoke Flux density (T) & 13206.8 & 35146 & Total iron loss (W) \\
1.65 & 1.78 & Stator tooth flux density (T) & 16233.6 & 33650 & Total copper loss (W) \\
72 & 79.7 & Rated stator current (A) & 2.8 & 2.5 & Break-down torque (p.u.) \\
0.5 & 0.58 & Average Air-gap flux density (T) & 2990 & 2987 & Rated speed (rpm) \\
0.8 & 0.75 & Starting torque (p.u.) & 750 & 700 & Outer diameter (mm) \\
441.9 & 612.3 & Rotor bar current (A) & 755 & 850 & Axial length (mm) \\
\hline
\end{tabular}

the resulted machine and thus, the effectiveness of the proposed design procedure.

In Table 13, the operating characteristics of the optimally designed machine resulting from the analytical model are compared with the results of $2 \mathrm{D}-\mathrm{FE}$ model in order to validate the accuracy of the proposed analytical design procedure. It can be seen that the results are in good coincidence.

\section{Conclusion}

In this paper, a comprehensive optimal electromagnetic-thermal design procedure was proposed for a 1-MW 7-phase induction motor. The coupled-circuit model of this motor was obtained and assessed to evaluate the important quantities and design variables. In order to achieve the model, 


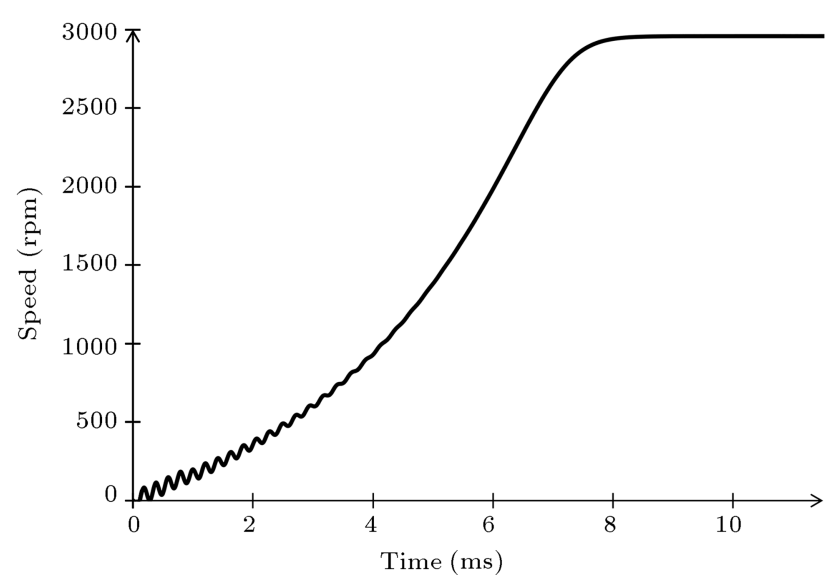

Figure 10. Rotating speed of the optimum designed 7-phase induction motor.

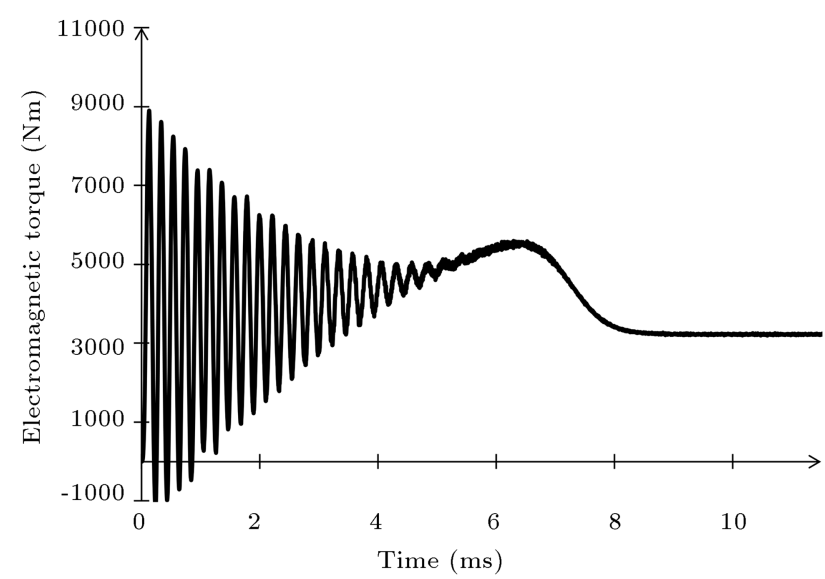

Figure 11. Electro-magnetic torque of the optimum designed 7-phase induction motor.

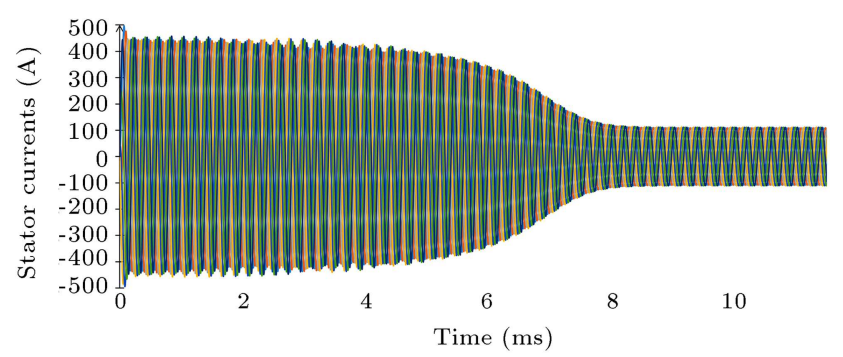

Figure 12. Stator winding currents of the optimum designed 7-phase induction motor.

the coil and turn functions were obtained and then, the self and mutual inductances between all windings of 7-phase motor were calculated using these functions. The coupled-circuit model was simulated in MATLAB/Simulink environment and the corresponding curves were obtained using motor quantities and dimensions. A lumped parameter thermal model was extracted in order to estimate the temperature rises in all regions, particularly in the stator winding insulation. By using the developed

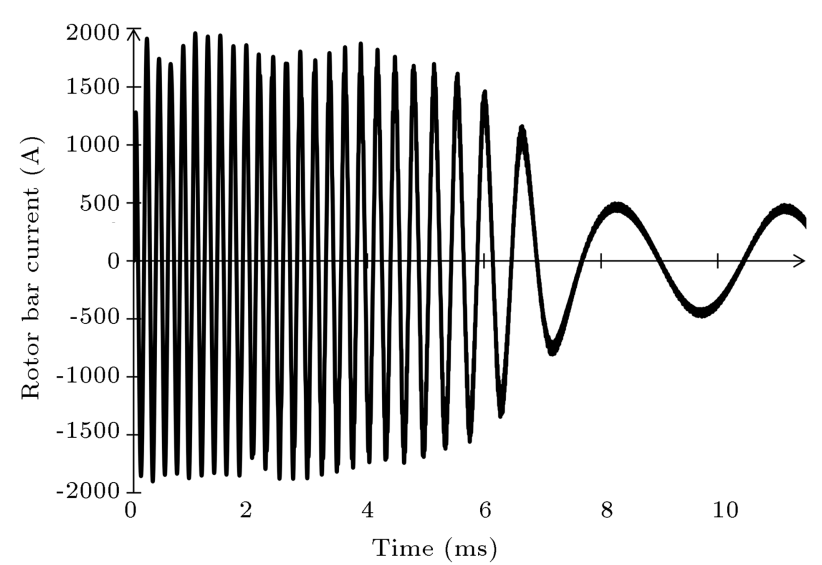

Figure 13. Rotor bar current of the optimum designed 7-phase induction motor.

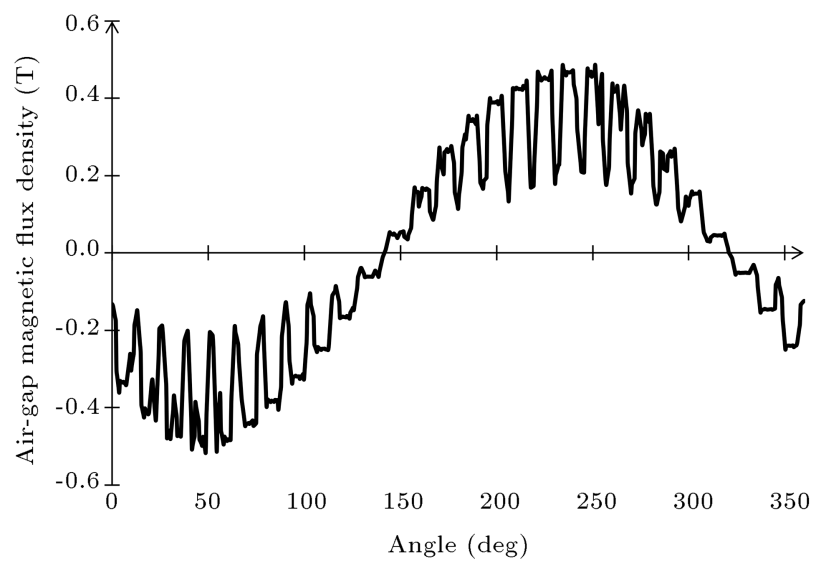

Figure 14. Air-gap flux density waveform of the optimum designed 7-phase induction motor.

models, defining a multi-purpose objective function, and considering several constraints, an optimal design procedure was established. The optimal specifications of an $1 \mathrm{MW}, 6 \mathrm{kV}, 4$ pole 7 -phase induction motor were evaluated using the proposed design flowchart. In order to evaluate the design accuracy, the machine model was analyzed using 2D-FE method. The results obtained for power, torque, currents and flux

Table 13. Comparison of operating parameters of optimum designed machine resulted from analytical and 2D-FE modes.

\begin{tabular}{lcc}
\hline \multicolumn{1}{c}{ Parameter (unit) } & $\begin{array}{c}\text { Analytical } \\
\text { model }\end{array}$ & $\begin{array}{c}\text { 2D-FE } \\
\text { model }\end{array}$ \\
\hline Power factor & $90 \%$ & $91 \%$ \\
Efficiency & $97 \%$ & $96.8 \%$ \\
Total iron loss (W) & 13206.8 & 13825.4 \\
Total copper loss (W) & 16233.6 & 18436.7 \\
Rated speed (rpm) & 2990 & 2989.2 \\
No-load current (A) & 22.7 & 23.6 \\
Rated current (A) & 73.3 & 74.8 \\
Average air-gap flux density (T) & 0.5 & 0.47 \\
\hline
\end{tabular}




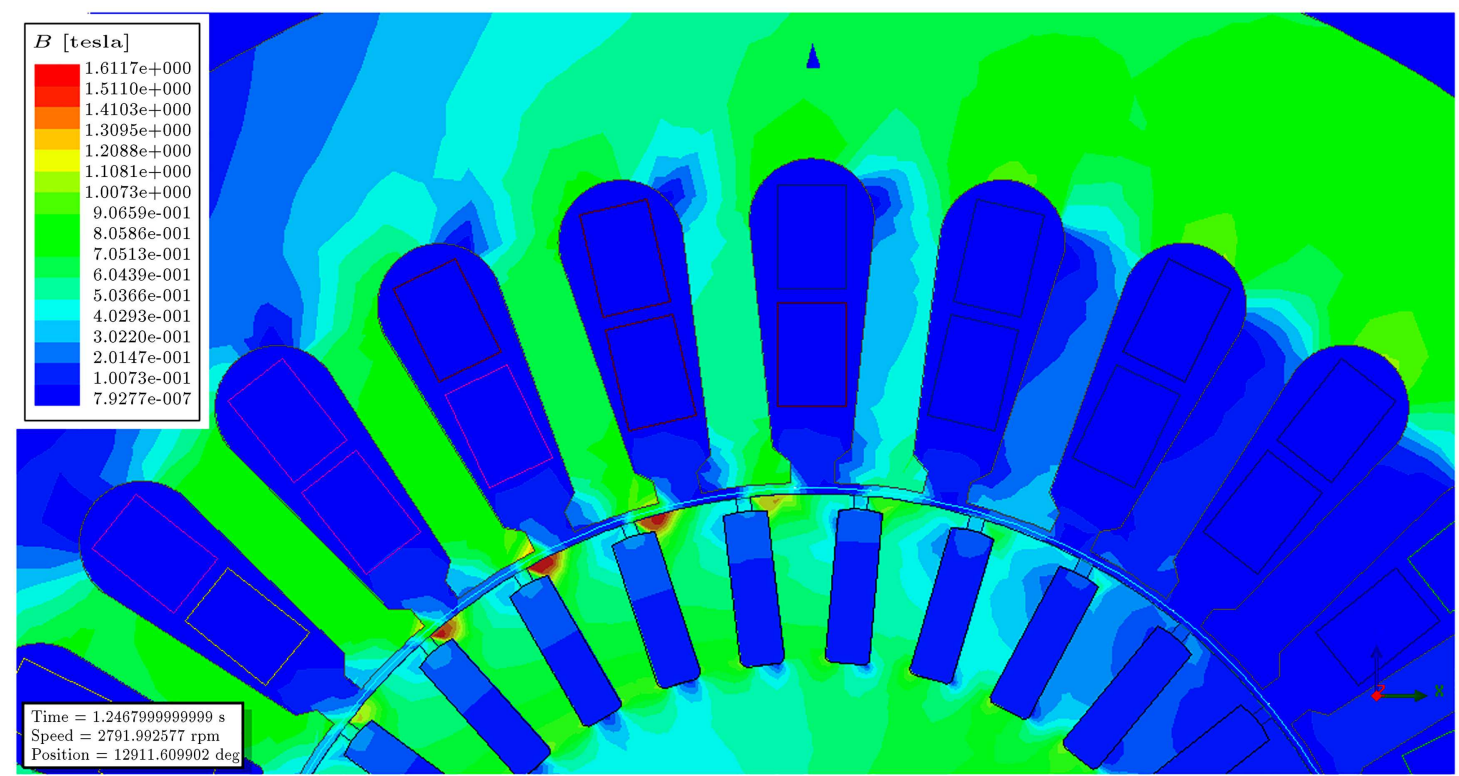

(a)

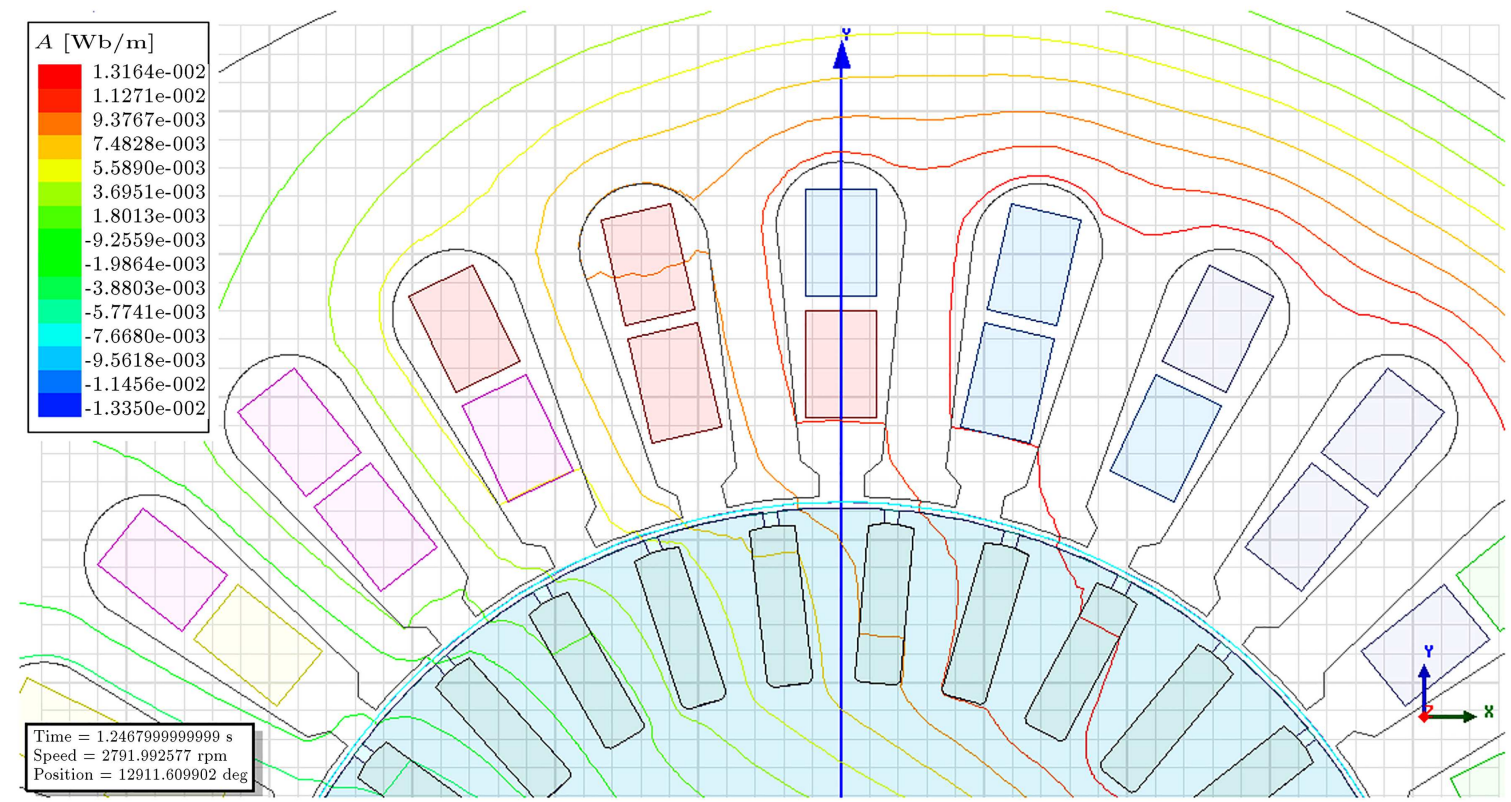

(b)

Figure 15. 2D views of (a) Flux density distribution and (b) flux lines in cross-section of the optimum designed 7-phase induction motor.

densities were in good agreement with the analytically predicted values. The lower starting and full-load current of stator windings with smoother torque and speed waveforms of the designed 7-phase motor in comparison to the similar rated 3-phase motor revealed that it was a suitable choice for high-rated and variable-speed applications.

\section{References}

1. Ward, E.E. and Harer, H. "Preliminary investigation of an inverter-fed 5-phase induction motor", Proc. Inst. Elect. Eng., 116(6), pp. 980-984 (1969).

2. Klingshirn, E.A. "High phase order induction motorsPart I-description and theoretical considerations", IEEE Transactions on Power Apparatus and Systems, PAS-102(1), pp. 47-53 (1983).

3. Klingshirn, E.A. "High phase order induction motorsPart II-experimental results", IEEE Transactions on Power Apparatus and Systems, PAS-102(1), pp. 5459 (1983).

4. Singh, G.K. "Multi-phase induction machine drive 
research-a survey", Electr. Power Syst. Res., 61, pp. 139-147 (2002).

5. Jones, M. and Levi, E. "A literature survey of stateof-the-art in multiphase AC drives", Proc. Universities Power Engineering Conference UPEC, Stafford, UK, pp. 505-510 (2002).

6. Levi, E., Bojoi, R., Profumo, F., et al. "Multiphase induction motor drives-A technology status review", IET Elect. Power Appl., 1(4), pp. 489-516 (2007).

7. Martin, C., Arhal, M.R., and Barrero, F. "Fivephase induction motor rotor current observer for finite control set model predictive control of stator current", IEEE Transactions on Industrial Application, 63(7), pp. $4527-4538$ (2017).

8. Levi, E. "Multiphase electric machines for variablespeed applications", IEEE Trans. Ind. Electron., 55(5), pp. 1893-1909 (2008).

9. Kong, W., Qu, R., and Kang, M. "Air gap and Yoke flux density optimization for multiphase induction motor based on novel harmonic current injection method", IEEE Transactions on Industrial Application, 53(3) (2017).

10. Abdel-Khalik, A.S., Gadoue, S.M., Masoud, M.I., et al. "Optimum flux distribution with harmonic injection for a multiphase induction machine using genetic algorithm", IEEE Transactions on Energy Conversion, 26(2), pp. 501-512 (2011).

11. Lin, C.H. and Hwang, C.C. "Multiobjective optimization design for a six-phase copper rotor induction motor mounted with a scroll compressor", IEEE Transactions on Magnetics, 52(7), pp. 1-4 (2016).

12. Pereira, L.A., Scharlau, C.C., Alves Pereira, L.F., et al. "General model of a five-phase induction machine allowing for harmonics in the air gap field", IEEE Transactions on Energy Conversion, 21(4), pp. 891899 (2006).

13. Duran, M.J., Salas, F., and Arahal, M.R. "Bifurcation analysis of five-phase induction motor drives with third harmonic injection", IEEE Transactions on Industrial Electronics, 55(5), pp. 2006-2014 (2008).

14. Lyra, R.O.C. and Lipo, T.A. "Torque density improvement in a six-phase induction motor with third harmonic current injection", IEEE Transactions on Industry Application, 38(5), pp. 1351-1360 (2012).

15. Gorginpour, H. "Dual-stator consequent-pole vernier PM motor with improved power factor", IET Electric Power Applications, 13(5), pp. 652-661 (2019).

16. Barrero, F. and Duran, M.J. "Recent advances in the design, modeling, and control of multiphase machinesPart I", IEEE Transactions on Industrial Electronics, 63(1), pp. 449-458 (2016).

17. Barrero, F. and Duran, M.J. "Recent advances in the design, modeling, and control of multiphase machinesPart II", IEEE Transactions on Industrial Electronics, 63(1), pp. 459-468 (2016).
18. Lipo, T.A., Introduction to AC Machine Design, 2nd Ed., University of Wisconsin Madison (2004).

19. Fu, F. and Tang, X., Induction Machine Design Handbook, China Machine Press (2002).

20. Vishnu Murthy, K.M. and Narayanamma, G. "Computer-aided design of electrical machines", BS Publications, Giriraj Lane, Sultan Bazar (2008).

21. Nanoty, A.S. and Chudasama, A.R. "Design of multiphase induction motor for electric ship propulsion", IEEE Electric Ship Technologies Symposium, Alexandria, VA, pp. 283-287 (2011).

22. Levi, E., Bojoi, R., Profumo, F., et al. "Multiphase induction motor drives- a technology status review", IET Electric Power Applications, 1(4), pp. 489-516 (2007).

23. Wu, Z. and Ojo, O. "Coupled-circuit-model simulation and airgap-field calculation of a dual-stator-winding induction machine", IEE Proceedings - Electric Power Applications, 153(3), pp. 387-400 (2006).

24. Asgari, S., Yazdanpanah, R. and Mirsalim, M. "A dual-stator machine with diametrically magnetized PM: Analytical air-gap flux calculation, efficiency optimization and comparison with conventional dualstator machines", Scientia Iranica, 29(1), pp. 208-216 (2022). DOI: $10.24200 /$ sci.2019.53316.3181

25. Farshadnia, M., Masood Cheema, M.A., Pouramin, A., et al. "Design of optimal winding configurations for symmetrical multiphase concentrated-wound surfacemount PMSMs to achieve maximum torque density under current harmonic injection", IEEE Transactions on Industrial Electronics, 65(2), pp. 1751-1761 (2018).

26. Caruso, M., Tommaso, A.O.D., Miceli, R., et al. "Computer-aided analysis and design procedure for rotating induction machine magnetic circuits and winding", IET Electer Power Apple, 12(6), pp. 885893 (2018).

27. Boglietti, A., Cavagnino, A., and Staton, D. "Determination of critical parameters in electrical machine thermal model", IEEE Trans. Ind. Appl., 44(4), pp. 1150-1159 (2008).

28. Huai, Y., Melnik, R.V.N., and Thogersen, P.B. "Computational analysis of temperature rise phenomena in electric induction motors", Elsevier Journal of Applied Thermal Engineering, 23, pp. 779-795 (2003).

29. Rouhani, H., Faiz, J., and Lucas, C. "Lumped thermal model for switched reluctance motor applied to mechanical design optimization", Elsevier Journal of Mathematical and Computer Modelling, 45(5), pp. 625-638 (2007).

30. Makni, Z., Besbes, M., and Marchand, C. "Multiphysics design methodology of permanent-magnet synchronous motors", IEEE Trans. Vehicular Technology, 56(4), pp. 1524-1530 (2007).

31. Alberti, L. and Bianchi, N. "A coupled thermalelectromagnetic analysis for a rapid and accurate prediction of IM performance", IEEE Trans. Ind. Electron., 55(10), pp. 3575-3582 (2008). 
32. Gorginpour, H., Oraee, H., and McMahon, R.A. "Electromagnetic-thermal design optimization of the brushless doubly fed induction generator", IEEE Transactions on Industrial Electronics, 61(4), pp. 1710-1721 (2014).

\section{Biographies}

Zargham Heidari was born in Noorabad Mamasani, Iran in 1970. He received his BSc degree in Electrical Engineering from Shiraz Technical University in 1995. He received his MSc degree in Electronic Engineering from the Faculty of Electrical Engineering of Najaf Abad Branch, Islamic Azad University in 1998. He has been teaching at the Islamic Azad University of Bushehr as a member of the Faculty of Electrical Engineering since 1999. His favorite research areas are power electronics and electric machines. He has been studying $\mathrm{PhD}$ in Electrical Power at the Islamic Azad University of Bushehr for six years and is currently writing his dissertation.

Hamed Gorginpour was born in Bushehr, Iran in 1985. He received the BSc degree in Electrical Engineering from Shiraz University, Shiraz, Iran in
2007 and MSc and PhD degrees from Sharif University of Technology (SUT), Tehran, Iran in 2009 and 2014, respectively. He is currently an Assistant Professor at Persian Gulf University (PGU), Bushehr, Iran. His research interests include electrical machine design and modelling, finite element analysis, and power electronics and drives.

Mahdi Shahparasti received the $\mathrm{PhD}$ degree in Electrical Engineering specializing in Power Electronics from Tarbiat Modares University, Tehran, Iran in 2014. For 7 years, between 2010-2014 and 2016-2017, he was a Research and Development Researcher with JDEVS Company, Tehran, designing medium and high power converters. Moreover, in 2016, he served as an Assistant Professor at the Department of Electrical Engineering, East Tehran Branch, Islamic Azad University, Tehran. During 2015 and 2017-2019, he was a Postdoctoral Researcher at the Technical University of Catalonia, Barcelona, Spain, where he was involved in the control of high-power grid-connected converters. He is currently a postdoc researcher at the University of Southern Denmark. His current research interests include control standalone and grid-connected inverters, renewable energy resources, and motor drive systems. 